\title{
Effect of Attapulgite Nanorods and Calcium Sulfate Microwhiskers on the Reaction-Induced Phase Separation of Epoxy/PES Blends
}

\author{
Xiaolin Tang, Xinhui Zhong, Guozhu Zhan, Yingfeng Yu, and Hongdong Zhang \\ State Key Laboratory of Molecular Engineering of Polymers, Department of Macromolecular Science, Fudan University, \\ Shanghai 200433, China
}

Correspondence should be addressed to Hongdong Zhang; zhanghd@fudan.edu.cn

Received 15 April 2013; Accepted 4 June 2013

Academic Editor: Jan-Chan Huang

Copyright (C) 2013 Xiaolin Tang et al. This is an open access article distributed under the Creative Commons Attribution License, which permits unrestricted use, distribution, and reproduction in any medium, provided the original work is properly cited.

\begin{abstract}
The influence of two kinds of mesoscale inorganic rod fillers, nanoscale attapulgite and micron-sized $\mathrm{CaSO}_{4}$ whisker, on the reaction-induced phase separation of epoxy/aromatic amine/poly- (ether sulfone) (PES) blends has been investigated by optical microscopy $(\mathrm{OM})$, scanning electron microscopy (SEM), and time resolved light scattering (TRLS). By varying the PES concentration and curing temperature, we found that the incorporation of attapulgite and $\mathrm{CaSO}_{4}$ had dramatic impact on the phase separation process and the final phase morphology of blends. In blends at higher content than critical concentration, the process of phase separation was retarded by the incorporation of nanoscale fillers but accelerated by that of the micron-sized fillers, mainly due to the enhanced viscoelastic effect and the preferential wettable effect, respectively. Meanwhile both mesoscale fillers could change the cocontinuous phase structure of blends with lower PES content than critical concentration into PES-rich dispersed structure due to the surface affinity of fillers to epoxy matrix.
\end{abstract}

\section{Introduction}

It has been generally accepted that phase separation plays a significant role in determining the morphology and properties of polymer mixtures. The reaction-induced phase separation in thermosets/thermoplastic blend is a very important physical/chemical process, which has aroused wide interest for many years [1-12].

Recently, it has been found that the incorporation of inorganic filler has dramatic impact on the phase separation behavior and the final phase structure of binary polymer mixture and thermosets/thermoplastic blends [13-18], especially when the fillers are preferentially wettable to one component.

For the ternary mixtures of polymer blends containing glass particles in micron size, Tanaka et al. [19] proved that both the coarsening dynamics and the final morphology were significantly affected by the mobility of glass particles and their selective inclusion of the more wettable phase.

By simulation, Balazs and coworkers pointed out that the addition of hard particles greatly changed both the speed and morphology of phase separation, and the phase separation is arrested in the late stage [20-22]. For the blends with mobile nanoscale rods, their simulation results show that the rods could self-assemble into needle-like and percolating network, and increasing the rod concentration beyond the effective percolation threshold could drive the system to self-assemble in a Lamellar morphology $[23,24]$. By a new simulation methodology, Side et al. indicated that the phase pattern of PS-P2VP diblock nanocomposite containing (PSs) functionalized Au particles changes as the nanoparticles density increases, which agreed well with experimental results [25].

For the polymerization-induced phase separation in nanoparticle-monomer-polymer blends, Soulé et al. [26] indicated that a small increase in particle size had an influential effect on extending the immiscibility region of the phase diagram by using the model proposed by Ginzburg [27].

In epoxy/rubber blends containing clay, Balakrishnan et al. [16] found that the clay concentration plays an important role in the clay platelet separation and the dispersion of 
TABLE 1: The weight compositions of the samples studied.

\begin{tabular}{lcccccc}
\hline Samples & PES-14.3 & PES-14.3-A & PES-14.3-Ca & PES-11.4 & PES-11.4-A & PES-11.4-Ca \\
\hline DGEBA (g) & 1.00 & 1.00 & 1.00 & 1.00 & 1.00 & 1.00 \\
DIM-DDM (g) & 0.32 & 0.32 & 0.32 & 0.32 & 0.32 & 0.32 \\
PES (g) & 0.22 & 0.22 & 0.22 & 0.17 & 0.17 & 0.17 \\
ATT (g) & 0 & 0.064 & 0 & 0 & 0 \\
CaSO $_{4}$ (g) & 0 & 0 & 0.064 & & 0 & 0.062 \\
\hline
\end{tabular}

clay aggregates in the epoxy matrix, while the clay platelets were preferentially absorbed into the rubber particles. For the blends of epoxy modified with thermoplastics, Peng et al. [17] had investigated the influence of nanoscale layered silicates on the reaction-induced phase separation behavior, which indicated that the incorporation of silicates had dramatic impact on the phase separation process and the final phase morphology, though the SD mechanism was entirely followed.

While in thermoplastic modified thermoset blends with dynamic asymmetry, the chain mobility difference of the two parts makes the viscoelastic effect play a crucial role in phase separation process [28]. The addition of nanoscale fillers further enhanced this viscoelastic effect from the chain entanglement of slow dynamic part with the filler surface, which significantly hindered the phase structure evolution process and thus results in a refined phase structure with much smaller characteristic length scales [29, 30].

However, it remained unclear that the effect of mesoscale fillers and their size on the phase separation process of systems with moderate curing rate and even secondary phase separation, though we found previously that the incorporation of nanoscale rods changed the final phase morphology due to the nanoscale fillers pinning down the phase separation by distributing along the interfaces between the epoxy-rich and PES-rich phases [31].

This article aimed to investigate the reaction-induced phase separation in Epoxy/PES blends containing different size of mesoscale inorganic rod fillers, ATT (nanoscale), and $\mathrm{CaSO}_{4}$ (microscale) rod, in particular, to examine the influence of incorporation of inorganic rod on the whole phase separation process, which would hopefully give us better understanding of the mechanism of reaction-induced phase separation.

\section{Experimental}

2.1. Materials and Samples Preparation. The epoxy oligomer DER331, a lower-molecular-weight liquid diglycidyl ether of bisphenol A (DGEBA) with an epoxide equivalent of 182-192, was purchased from Dow Chemical Co. PES ([ $\eta]$ (intrinsic viscosity) $=0.36$ ) was supplied by Jilin University (China). The curing agent 4,4'-methylene-bis(2,6-dimethylamiline) (DIM-DDM) was bought from Aldrich Chemical Co. Inc. (Germany). Attapulgite $\left(\mathrm{Si}_{8} \mathrm{O}_{20} \mathrm{Mg}_{5}(\mathrm{Al})(\mathrm{OH})_{2}\left(\mathrm{H}_{2} \mathrm{O}\right)_{4}\right.$, Attagel 50, Engelhard Co., United States) was surface modified by $\gamma$-methacryloxypropyltrimethoxysilane to improve its dispersing in epoxy resins. $\mathrm{CaSO}_{4}$ whiskers were provided by Shanghai Fuhua Industrial Co. (China) and used without further treatment.

A certain amount of ATT or $\mathrm{CaSO}_{4}$ rod was first dispersed in acetone under ultrasonication, the epoxy was then added to the suspension, and it was ultrasonicated again. Acetone was vaporized in a circulation oven at room temperature until most of the solvent was removed. After the samples were placed into vacuum oven at $100^{\circ} \mathrm{C}$ for $4 \mathrm{hrs}$, PES was added into the mixture of epoxy and inorganic rods and stirred fiercely at $150^{\circ} \mathrm{C}$ in an oil bath. When the mixture was then cooled to $100^{\circ} \mathrm{C}$, stoichiometric amount of DIM-DDM (32 phr to epoxy oligomer) was added, and the mixture was stirred before cooling rapidly to room temperature to avoid further curing. A series of blends were prepared as shown in Table 1, in which the amount of ATT and $\mathrm{CaSO}_{4}$ rod in two hybrid mixtures is the same of $4 \mathrm{wt} \%$, and the content of PES is its weight percent in the resin matrix (without fillers). For example, PES-14.3-A means PES content is $14.3 \%$ of PES/epoxy/DIM-DDM and ATT is $4 \%$ of total amount of composition.

2.2. Measurements. A PerkinElmer Pyris 1 DSC instrument was used for the study of the curing reaction. The isothermal curing conversion was calculated from residual exotherms observed in scans in the temperature range of $50-350^{\circ} \mathrm{C}$, with heating rates of $10^{\circ} \mathrm{C} / \mathrm{min}$ and normalized by the total exotherms for uncured samples. A Tescan TS5163MM scanning electron microscope was employed to examine the morphologies of the fractured surfaces (the samples were first cured at specific temperature for 5 hours, then postcured at $150^{\circ} \mathrm{C}$ for 5 hours, then fractured in liquid nitrogen, and coated with gold). The phase separation process during isothermal curing was traced in situ on a self-made TRLS apparatus with a controllable hot chamber. The change in the light scattering profiles was recorded at appropriate time intervals. The samples for TRLS observation were sandwiched between two glass cover slides and pressed into thin film. In the light scattering experiment, information on the phase morphology evolution could be obtained from the systematic change in the curves of the scattering factor versus the scattering light intensity as a function of the time of phase separation, and the most probable phase domain size was $d_{m}$ $=2 \pi / q_{m}$, where $q_{m}$ is the peak scattering vector. The evolving morphologies of the samples were observed in situ with an XDS-1B optical microscope with a hot chamber (Chongqing Optical and Electrical Instrument Co., Ltd., China). 


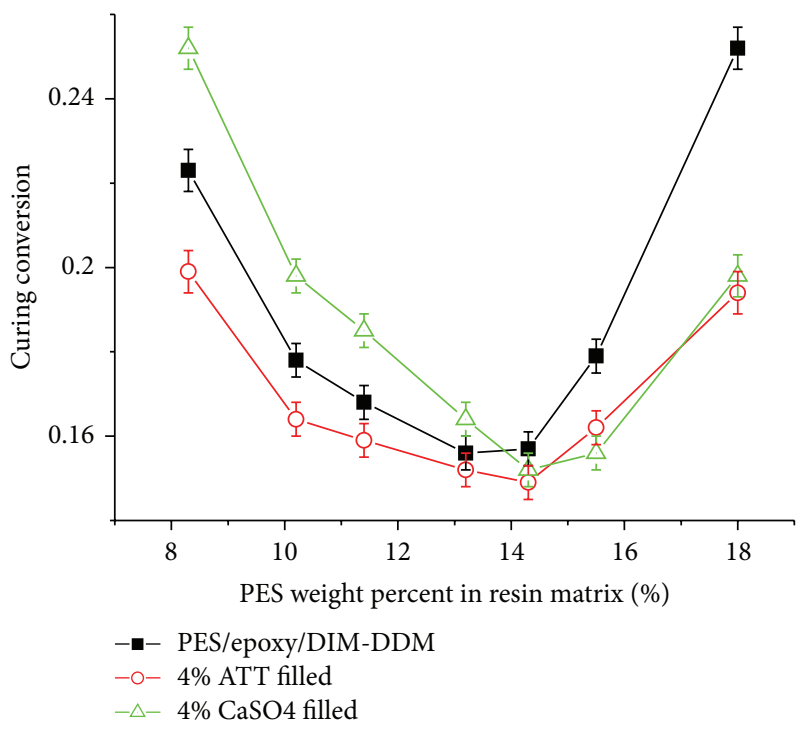

FIgURE 1: The phase diagram of the PES modified epoxy-hardener systems with and without fillers at $120^{\circ} \mathrm{C}$.

\section{Results and Discussions}

3.1. Effect of Mesoscale Fillers on the Phase Diagram. It is well known that the mixture of epoxy precursor and PES exhibits a lower critical solution temperature (LCST) phase behavior [32], including the following: the hardener changes the polarity of the mixture and thus makes the phase decomposition follow a reaction-induced phase separation process, in which the homogenous mixture separates into two phases after the cloud point (with specific curing conversion).

Figure 1 shows the phase diagram of PES/epoxy/DIMDDM blends without and with mesoscale fillers cured at $120^{\circ} \mathrm{C}$. As the epoxy and PES have lower solubility with the increase in temperature, the mixtures begin to phase separate at lower curing conversion when the curing temperature is increased. For the blends cured at $140^{\circ} \mathrm{C}$ (not shown here), the curing conversions at the initial phase separation are all below $6 \%$ of curing conversion at the PES concentration range of $8 \mathrm{wt} \%$ to $18 \mathrm{wt} \%$. As the curing conversions are too low to be accurately differentiated of systems with and without fillers at the cloud points, the phase diagram at $140^{\circ} \mathrm{C}$ was not shown here. In Figure 1, it can be found that the critical concentration of the PES/epoxy/DIM-DDM is located near $13 \%$ of PES. The addition of mesoscale fillers changes the phase diagram to some extent. The nanoscale ATT advances the curing conversion of systems a little earlier, while the general shape of the phase diagram keeps similar to that of systems without fillers. This conversion change of phase diagram could be resulted from the nucleation effect of nanoscale fillers, which makes the phase separation be observed a little earlier when the dimension of concentration fluctuation is comparable to the size of fillers.

However, the introduction of micron-sized $\mathrm{CaSO}_{4}$ fillers shifts the critical concentration of PES to about $15 \%$ in the resin matrix. As the $\mathrm{CaSO}_{4}$ fillers show better affinity to the epoxy phase, this kind of dilute effect of PES could come from the prior distribution of fillers in epoxy phase [19].
To study the effect of fillers on the phase separation, we therefore choose two compositions of $14.3 \mathrm{wt}$ and $11.4 \mathrm{wt} \%$ PES in the resin matrix, which are located at both sides of critical concentration. The selection of blends with near critical composition guarantees the phase separation following spinodal decomposition (SD) mechanism, and thus the whole process could be well characterized by TRLS.

3.2. Double Phase Separation in PES Modified Epoxy without Fillers. The process of morphology evolution in unfilled blends with $14.3 \mathrm{wt} \%$ and $11.4 \mathrm{wt} \%$ of PES follows the SD mechanism due to the nearly critical concentration. Figure 2 shows both the phase separation process and final morphology of PES-14.3 and PES-11.4 blends.

The morphology evolution of unfilled blend shows the feature of typical viscoelastic phase separation proposed by Tanaka [33]. After incubation time, the epoxy-rich (fast dynamic phase-rich) particles start to appear ((a2) and (e2)) and their size increases with time. Then the PES-rich (slow dynamic phase-rich matrix) particles become network-like with the growth epoxy-rich particles, and the thin parts of the network-like structure are elongated and broken, and finally the epoxy-rich dispersed sea-island phase structure was frozen by gelation or vitrification in the PES-14.3 blend ((a3) and (b)). For the PES-11.4 blend, the cocontinuous phase structure could be observed in the late stage of the phase separation ((e3) and (f)). It is noticeable that the secondary phase separation took place in both primary epoxy- and PESrich matrix (namely, in fast- and slow-dynamic-rich phase, (a3), (b), (e3), and (f)).

SEM micrographs show the usual phase-in-phase morphology in the PES-14.3 and PES-11.4 blends. The secondary phase separation took place in both primary epoxy-rich and PES-rich phases in these two blends cured at 120 and $140^{\circ} \mathrm{C}$. It indicates that the secondary PES-rich particles disperse in the primary epoxy-rich matrix ((c2) and (g2)) and the secondary epoxy-rich particles disperse in the primary silk-like PESrich domain ((c3) and (g3)). This structure is commonly similar to that described previously [34].

For the PES-11.4 blend, it is could be observed that the co-continuous phase morphology due to the higher concentration of epoxy resin and the lower viscosity (viz., weaker elastic strength of PES-rich domain). In the blend with higher PES concentration (PES-14.3 blend), after the epoxy-rich particles taking place, the increase in size of these particle was restrained by the stronger strength of PES-rich domain. In the above mentioned two blends, the secondary phase separation takes place as a result of the quench going deeper along with the epoxy resin reaction proceeding [1].

\subsection{Competition of Enhanced Viscoelastic Effect and Surface} Wetting Effect of Mesoscale Fillers on the Phase Separation at Higher PES Content Than Critical Concentration. The phase separation evolution process and final morphology of the two mesoscale fillers added PES-14.3 blends are shown in Figure 3. 


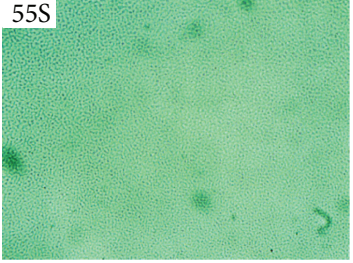

(a1)

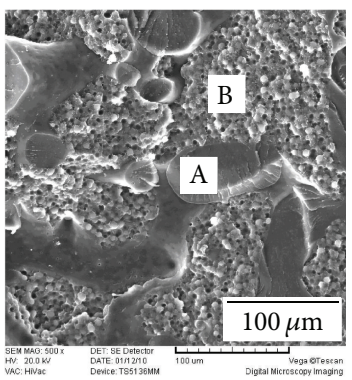

(c1)

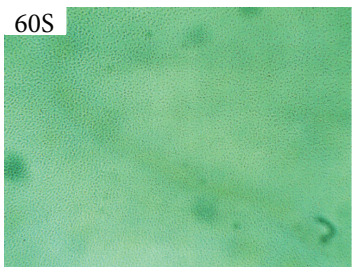

(e1)

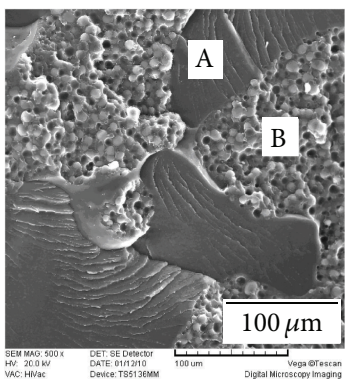

(g1)

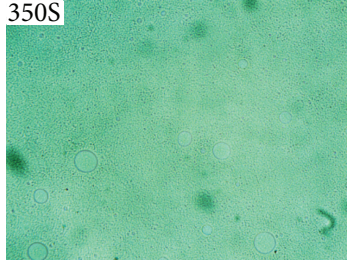

(a2)

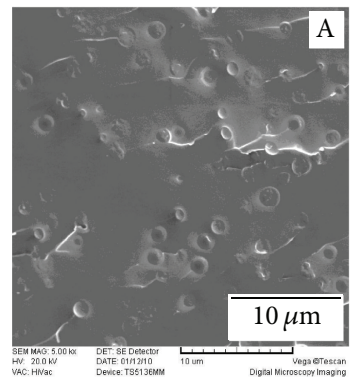

(c2)

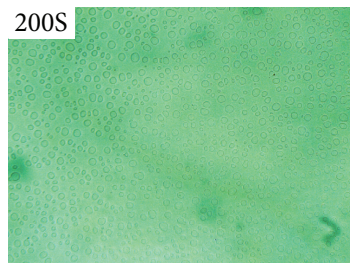

(e2)

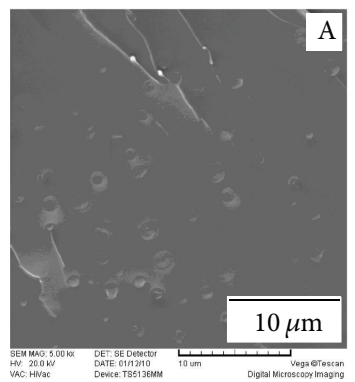

(g2)

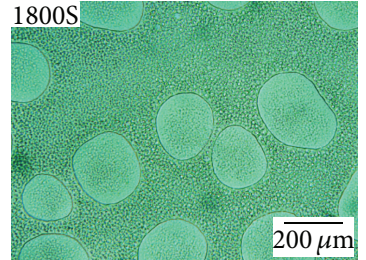

(a3)

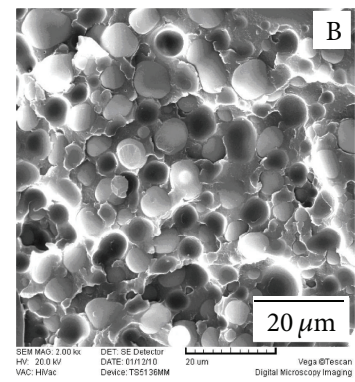

(c3)

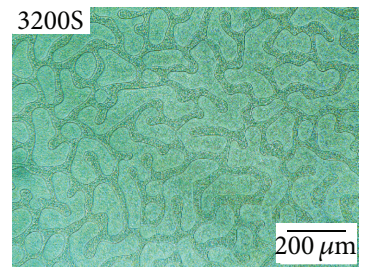

(e3)

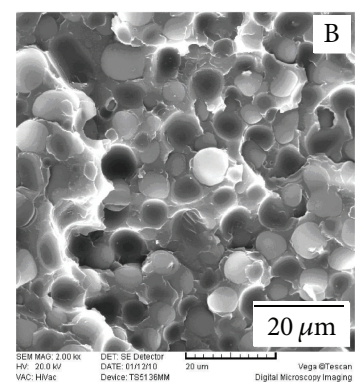

(g3)

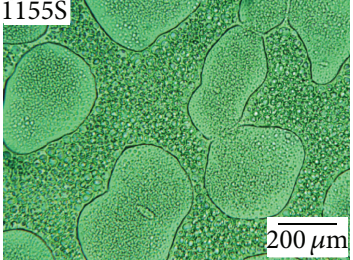

(b)

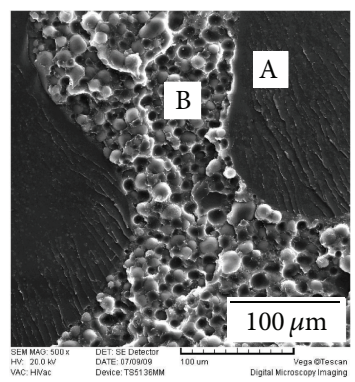

(d)

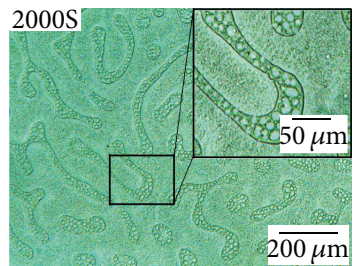

(f)

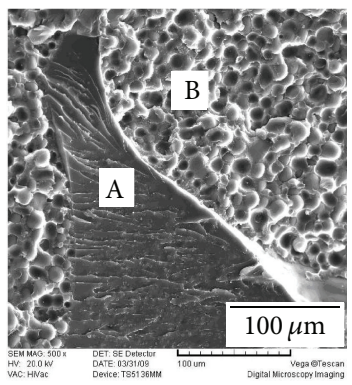

(h)

FIGURE 2: Development of morphologies of the blends followed by OM and SEM micrographs of the fracture surface of the blends. (a1)-(a3) PES-14.3 by OM at $120^{\circ} \mathrm{C}$; (b) finial morphology of PES-14.3 by OM at $140^{\circ} \mathrm{C}$; (c1)-(c3) PES-14.3 by SEM at $120^{\circ} \mathrm{C}$ for $5 \mathrm{~h}$; (d) PES-14.3 by SEM at $140^{\circ} \mathrm{C}$ for $5 \mathrm{~h}$; (e1)-(e3) PES-11.4 by OM at $120^{\circ} \mathrm{C}$; (f) finial morphology of PES-11.4 by OM at $140^{\circ} \mathrm{C}$; (g1)-(g3) PES-11.4 by SEM at $120^{\circ} \mathrm{C}$ for $5 \mathrm{~h}$; (h) PES-11. 4 by SEM at $140^{\circ} \mathrm{C}$ for $5 \mathrm{~h}$.

The ATT added systems show similar phase separation behavior as unfilled systems, in which the epoxy-rich phase shows as island structure dispersed in the PES-rich matrix ((a1), (a2), (a3), and (b)). The SEM micrographs ((c), (d1), (d2) is shown and (d3)) show a much refined phase structure of PES-14.3-A system compared with that of PES-14.3 (Figures 2(c1), 2(c2), 2(c3) and 2(d)), in which the interface between secondary PES-rich particle and primary epoxy-rich matrix (Figure 3(d2)), and that between secondary epoxyrich particle and primary membrane-like PES-rich phase (Figure 3(d3)) is no longer sharp due to the incorporation of the ATT.

The systems with $\mathrm{CaSO}_{4}$ seem to show similar behavior as PES-14.3 at both 120 and $140^{\circ} \mathrm{C}$ in the early-stage of phase separation. OM micrographs following morphology evolution shows a micro co-continuous structure initially (Figures 3(f1) and 3(f2)), and then small epoxy-rich particles form around the $\mathrm{CaSO}_{4}$ whisker (Figure 3(f3)) due to the $\mathrm{CaSO}_{4}$ whisker's effect of preferential wettable to the epoxy resin. However, SEM results indicate that $\mathrm{CaSO}_{4}$ whiskers are dispersed in both PES-rich and epoxy-rich phase, which implies that there may exist two different effects rather than the preferential affinity to epoxy.

TRLS is employed to investigate the differences between the systems with and without fillers, and the results were shown in Figure 4 . The changes in $q_{m}$ with phase evolution are illustrated for the higher PES content than critical composition cured at 120 and $140^{\circ} \mathrm{C}$. Figure 4(a) plots the 


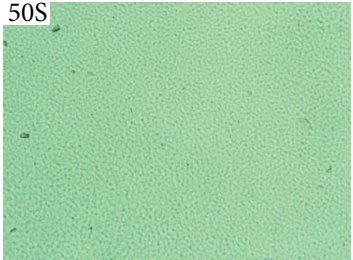

(a1)

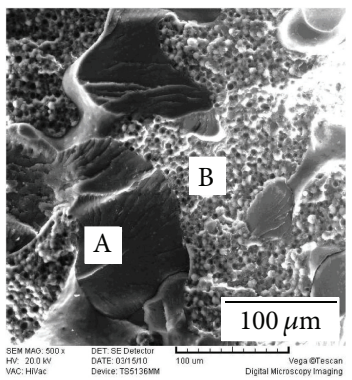

(c)

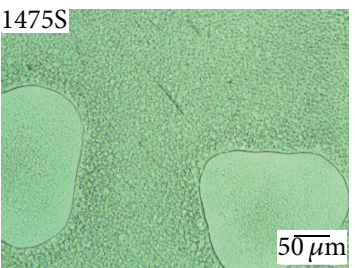

(e)

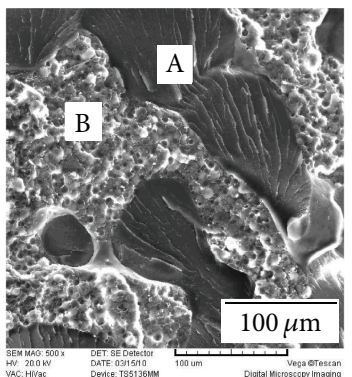

(g1)

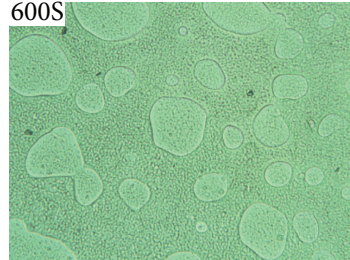

(a2)

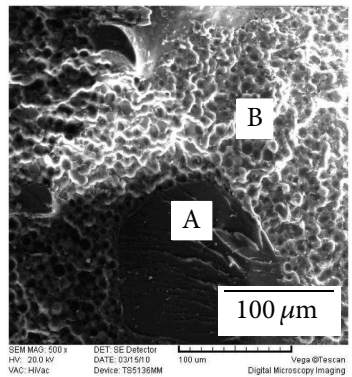

(d1)

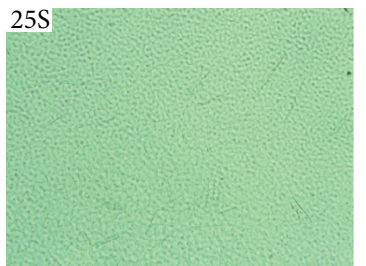

(f1)

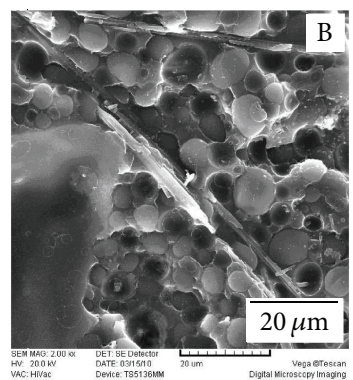

(g2)

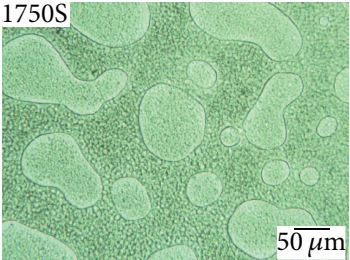

(a)

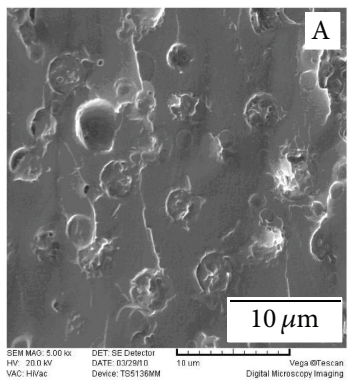

(d2)

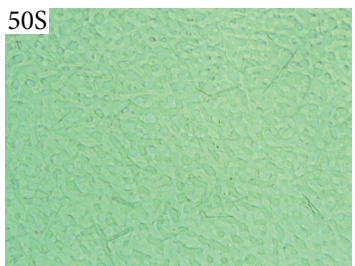

(f2)

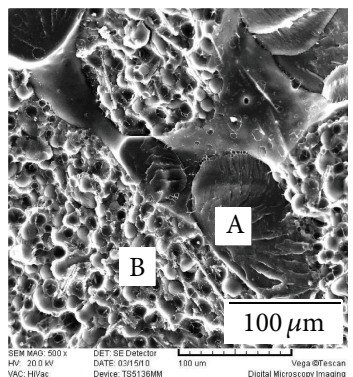

(h1)

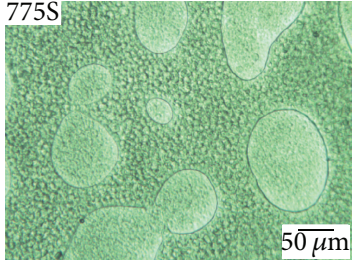

(b)

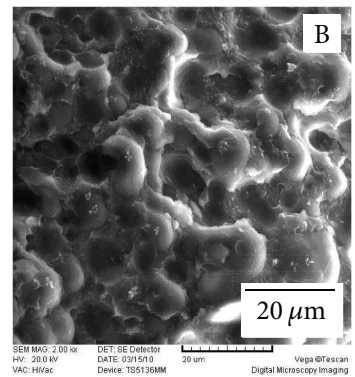

(d3)

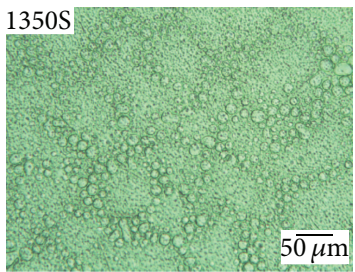

(f3)

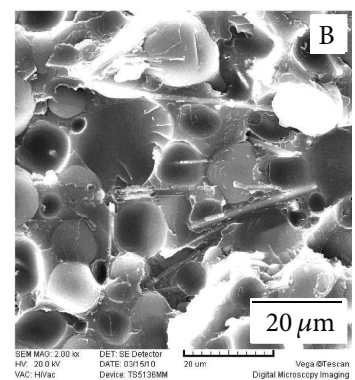

(h2)

FIGURE 3: Development of morphologies of the PES-14.3 blends with filler followed by OM and SEM micrographs of the fracture surface of these blends with filler. (a1)-(a3) PES-14.3-A by OM at $120^{\circ} \mathrm{C}$; (b) finial morphology of PES-14.3-A by OM at $140^{\circ} \mathrm{C}$; (c) PES-14.3-A by SEM at $120^{\circ} \mathrm{C}$ for $5 \mathrm{~h}$; (d1)-(d3) PES-14.3-A by SEM at $140^{\circ} \mathrm{C}$ for $5 \mathrm{~h}$; (e) finial morphology of PES-14.3-Ca by OM at $120^{\circ} \mathrm{C}$; (f1)-(f3) PES-14.3-Ca by $\mathrm{OM}$ at $140^{\circ} \mathrm{C}$; (g1) and (g2) PES-14.3-Ca by SEM at $120^{\circ} \mathrm{C}$ for $5 \mathrm{~h}$; (h1) and (h2) PES-14.3-Ca by SEM at $140^{\circ} \mathrm{C}$ for $5 \mathrm{~h}$.

PES-14.3-Ca cured at $140^{\circ} \mathrm{C}$ as an example of light scattering vector and intensity changing during phase separation. At the early stage of phase separation, $q_{m}$ shifted to lower value with a quick increase of light intensity, which indicates the phase structure growth with concentration varying. Then both $q_{m}$ and $I_{m}$ dropped quickly to a minimum value, at the same time, a second pick at high vector value grew up. The existence of minimum value in the curve of $q_{m}$ versus time means that appearance of secondary particles make the average phase domain size decrease.

For PES-14.3 cured at 120 and $140^{\circ} \mathrm{C}$, it could be found that the maximal slope of $\log q_{m}$ versus $\log t$ is 0.71 and
0.89, respectively. Elevated temperature increases the chain mobility and thus makes the phase separation a little quicker than that at lower temperature. The addition of nanoscale filler ATT in PES-14.3-A systems shifts the maximal slope to $0.41\left(120^{\circ} \mathrm{C}\right)$ and $0.50\left(140^{\circ} \mathrm{C}\right)$, meaning the phase evolution rate drops significantly. However, with the incorporation of micron-sized $\mathrm{CaSO}_{4}$, the maximal slope increases to 1.00 $\left(120^{\circ} \mathrm{C}\right)$ and $1.09\left(140^{\circ} \mathrm{C}\right)$, these unusually steep slopes mean that the size of the epoxy-rich domain grows rapidly in a short time, which clearly indicate the accelerating effect of this filler on the phase separation process. In other words, the incorporation of fillers show an opposite effect 


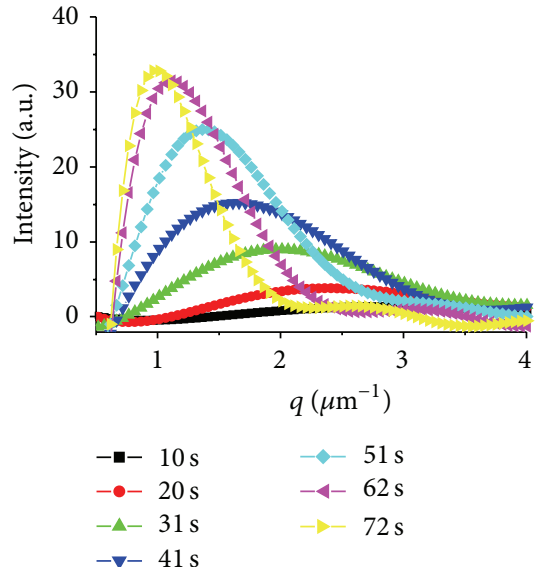

(a1)

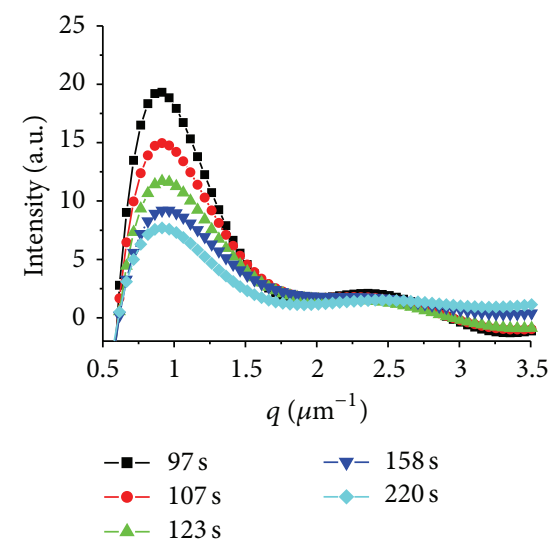

(a2)

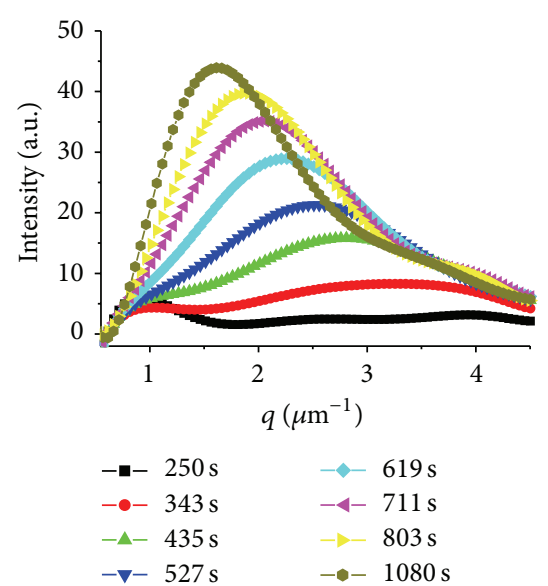

(a3)

(a)

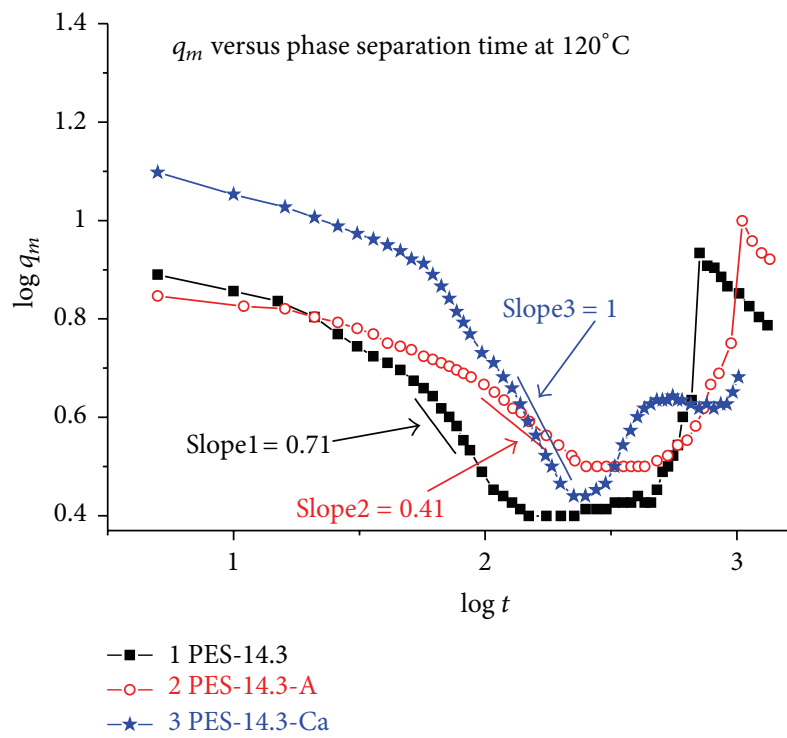

(b)

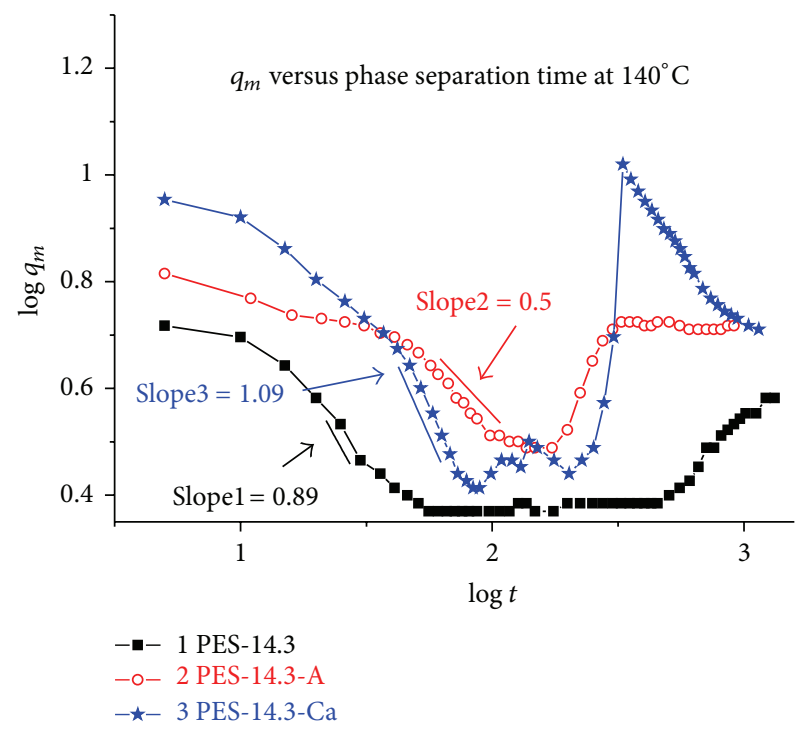

(c)

FIGURE 4: The changes of scattering vector, $q_{m}$, and light intensity versus time of the PES-14.3 blends with and without fillers. (a) PES-14.3-Ca cured at $140^{\circ} \mathrm{C}$, (b) $q_{m}$ versus time at $120^{\circ} \mathrm{C}$, and (c) $q_{m}$ versus time at $140^{\circ} \mathrm{C}$.

on the phase separation: the nanoscale fillers pin down the phase separation while micron-sized fillers accelerate the decomposition process at some stages.

On the basis of the above experimental results and previous works [19, 28-30], a possible scenario for the effect of mesoscale fillers on the phase separation of PES-modified epoxy blend could be as follows: in a dynamic asymmetric system with consider amount of slow dynamic components (PES at higher content than critical concentration), the diffusion of the fast dynamic epoxy-rich phase is prevented by the slow dynamic PES-rich phase, the addition of nanoscale fillers could enhance this process by the chain entanglement of slow dynamic phase with the filler surface due to the nanoscale fillers providing sufficient surface area $[29,30]$. Even though the nanoscale fillers have higher affinity to the fast dynamic phase, the elastic deformation of the slow dynamic phase could also form chain entanglement with the filler surface due to the high normal stress from the shear and shrink of the slow-dynamic phase. As a result, the nanoscale filler incorporated systems show a slower phase separation process compared to that of unfilled PES-epoxy-hardener systems, where the slopes of $\log q_{m}$ versus $\log t$ of nanoscale filler added systems are only about half values of those of unfilled systems at all the temperatures studied.

While for micron-sized $\mathrm{CaSO}_{4}$ whisker, which has a specific surface area about one tenth of that of ATT, the large filler size provide much smaller amount of entangle points with the slow dynamic phase, and thus this filler show less effect on the viscoelastic behavior of the phase separation process. Moreover, the high affinity of the micron-sized fillers to epoxy-rich phase further facilitate the growth of epoxyrich along the surface of the rod-fillers, which therefore 


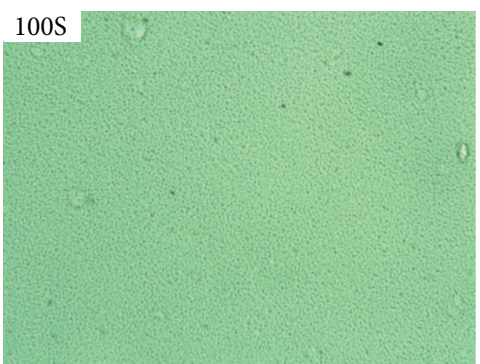

(a1)

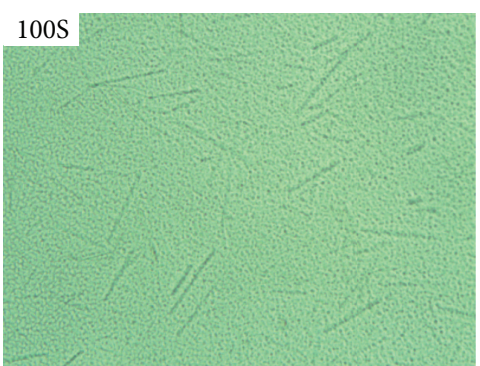

(b1)

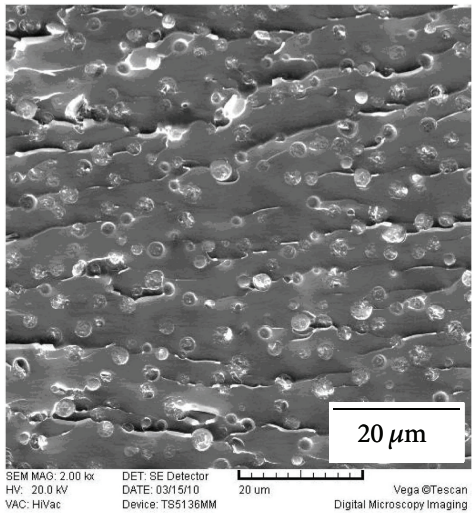

(c1)

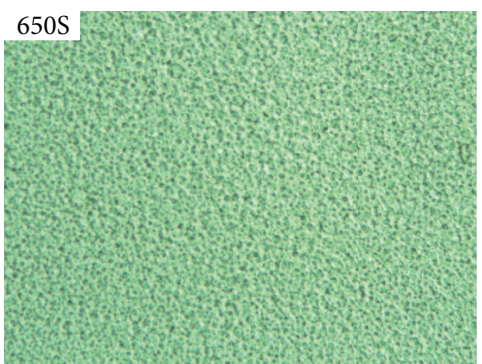

(a2)

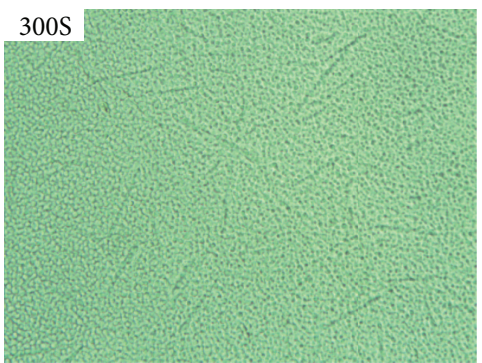

(b2)

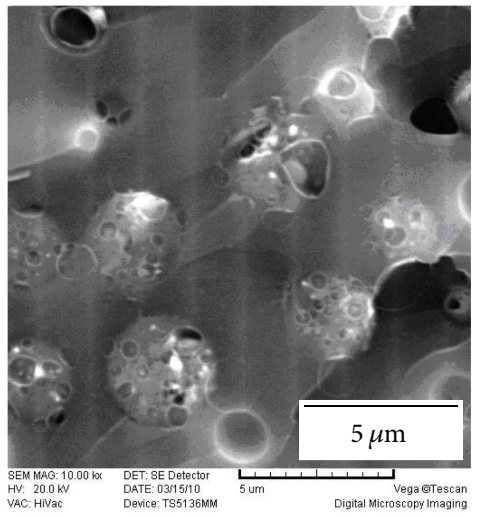

(c2)

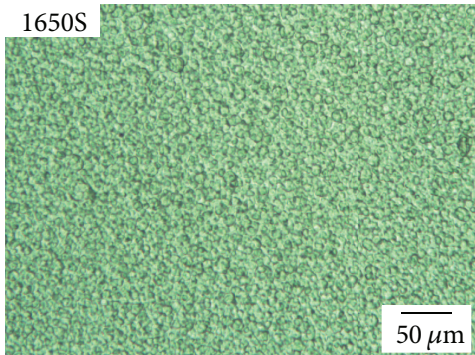

(a3)

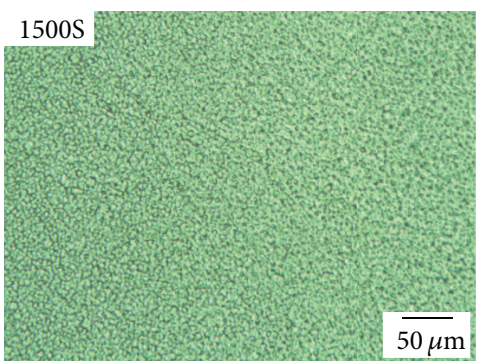

(b3)

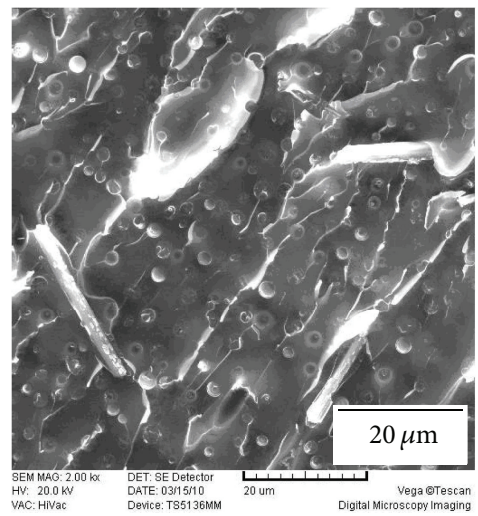

(d)

FIGURE 5: Development of morphologies of the PES-11.4 blend with fillers cured at $120^{\circ} \mathrm{C}$ followed by OM and SEM micrographs of the fracture surface of the blend with fillers cured at $120^{\circ} \mathrm{C}$ for $5 \mathrm{~h}$. (a1)-(a3) PES-11.4-A by OM; (b1)-(b3) PES-11.4-Ca by OM; (c1) and (c2) PES-11.4-A by SEM; (d) PES-11.4-Ca by SEM.

demonstrates a quick change in the peak scattering vector $q_{m}$ in TRLS due to the wetting effect of whiskers and interfacial tension of PES-rich phase [19].

From the above results, it seems that the influence of mesoscale fillers on the phase separation are mainly rely on the competition result of enhanced viscoelastic effect of the slow dynamic phase and surface wetting of the epoxy phase (fast dynamic phase) in our studied systems. Therefore, it can be inferred that surface wetting would be the main factor affecting phase separation in low dynamic asymmetric systems. To verify this point, the lower PES content (than critical concentration) systems are studied due to the diminished viscoelastic effect of these systems from lower volume fraction of slow dynamic phase.

3.4. Dilute Effect of Mesoscale Fillers at Lower PES Content. The phase evolution of mesoscale fillers added PES-11.4 blends (systems of lower content than critical concentration of PES) were followed by $\mathrm{OM}$ cured at $120^{\circ} \mathrm{C}$ (as shown in Figures 5(a1), 5(a2), 5(a3), 5(b1), 5(b2), and 5(b3)). The phase separation of mesoscale filler added systems shows distinct differences from that of unfilled PES-11.4 system (Figures 2(e1), 2(e2), 2(e3) and 2(f)). Although a micro co-continuous phase structure could also be observed at the initial stage of phase separation ((a1) and (b1)), the morphology then changes into PES-rich dispersed structure ((a2) and (b2)) and keeps to the end of the phase separation process ((a3) and (b3)).

SEM micrographs of the cured samples definitely indicate the PES-dispersed phase structure of the two mesoscale filler added systems (Figures 5(c1), 5(c2) and 5(d)). Furthermore, it can be clearly observed that a secondly phase separation still takes place in the PES-rich particles (Figure 5(c2)), while the mesoscale fillers are preferred to disperse in the epoxy matrix (Figure 5(d)) due to their high affinity. 


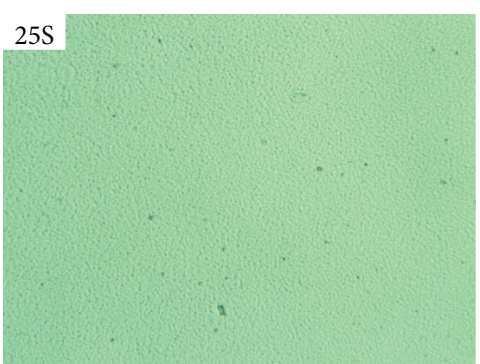

(a1)

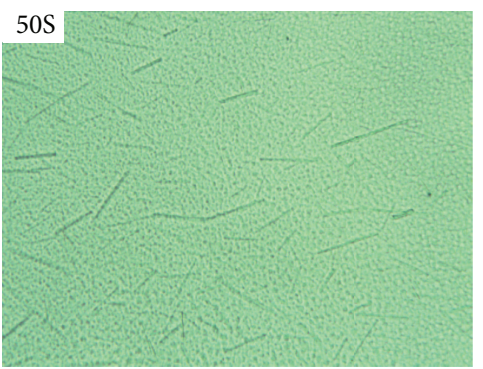

(b1)

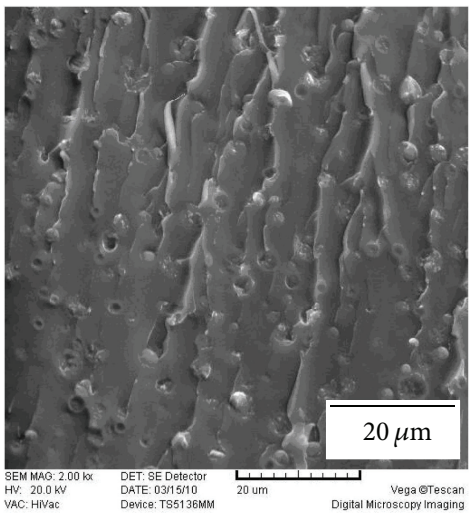

(c1)

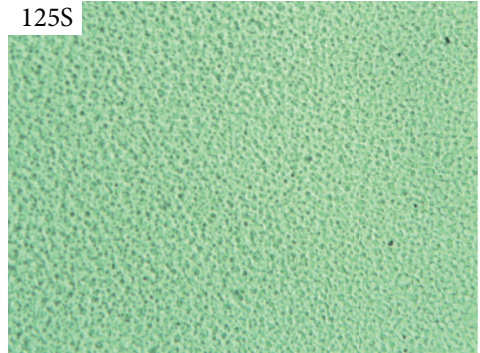

(a2)

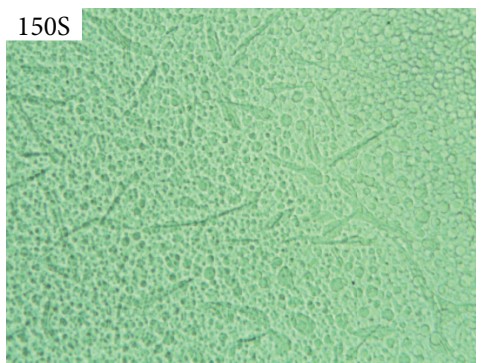

(b2)

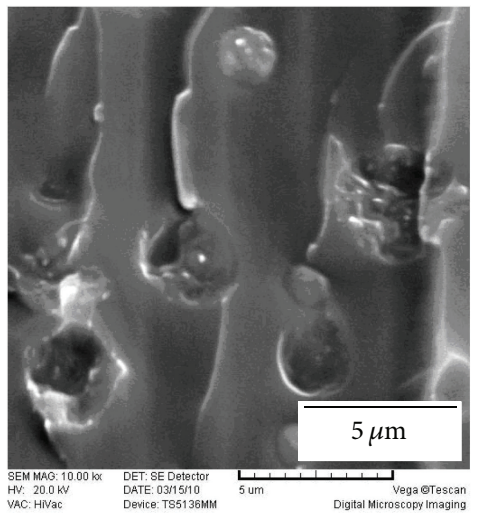

(c2)

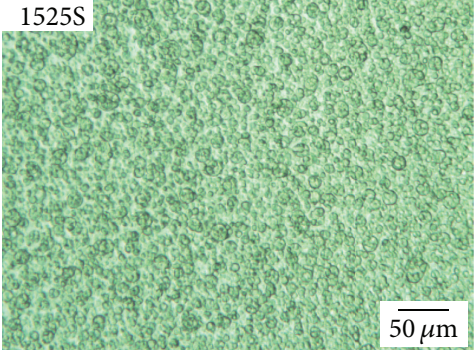

(a3)

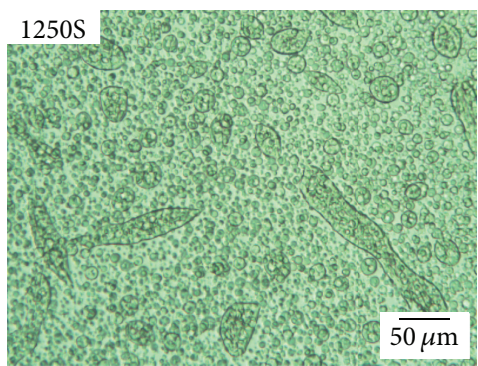

(b3)

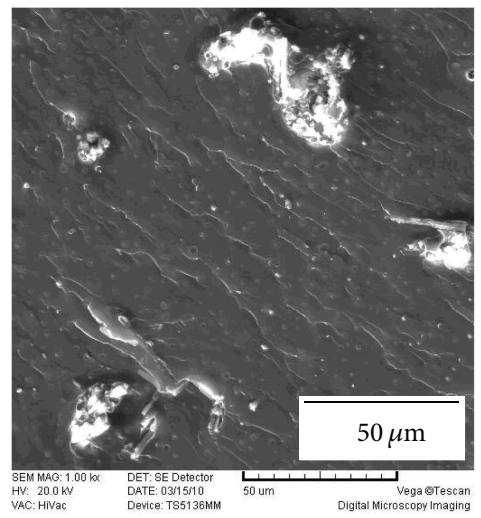

(d)

FIGURE 6: Development of morphologies of the PES-11.4 blend with fillers cured at $140^{\circ} \mathrm{C}$ followed by OM and SEM micrographs of the fracture surface of the blend with fillers cured at $140^{\circ} \mathrm{C}$ for $5 \mathrm{~h}$. (a1)-(a3) PES-11.4-A by OM; (b1)-(b3) PES-11.4-Ca by OM; (c1) and (c2) PES-11.4-A by SEM; (d) PES-11.4-Ca by SEM.

This kind of morphology change due to mesoscale fillers could also be observed at other curing conditions. As shown in Figure 6, filled systems cured at $140^{\circ} \mathrm{C}$ also proceed into PES-dispersed phase separation. Furthermore, the SEM micrographs show a PES-dispersed morphology (Figures 6(c1), (c2) and 6(d)) without secondary phase structure (Figure 6(c2)). In Figure 6(b1), 6(b2) and 6(b3), one could also found the aggregation of PES-particles along the whisker axis ((b2) and (b3)), which is deduced by the unmoved $\mathrm{CaSO}_{4}$ whisker blocking the PES-rich particles to reduce the interfacial energy [19].

According to Tanaka's theory, [33] the viscoelastic phase separation takes place most likely near critical concentration at deep quenches, while lower PES content always tend to be shifted to the traditional phase separation mechanisms due to the lower volume fraction of slow dynamic phase having shorter characteristic deformation time.
Even though the PES-11.4 system still follows viscoelastic phase separation, the incorporation of mesoscale fillers changes it into normal spinodal decomposition process due to the dilute effect of fillers and their high affinity to the epoxy-rich phase. The low volume fraction of PES (slow dynamic phase) results a quite short disentangle time of polymer chains, and thus the addition of nano fillers show limited enhancement effect on the viscoelastic phase separation. However, the affinity of both mesoscale fillers to epoxy phase show a dilute effect on PES concentration, furthermore, the domain growth of epoxy-rich along the filler percolation network sharpens the formation of epoxy matrix (or PES particle) structure [19].

TRLS results of PES-11.4 systems cured at $120^{\circ} \mathrm{C}$ showed quite similar slopes of $0.51,0.48$ and 0.55 for unfilled, nanoscale, and micron-size filled blends, respectively (Figure 7(a)). The addition of nano fillers slightly retards 


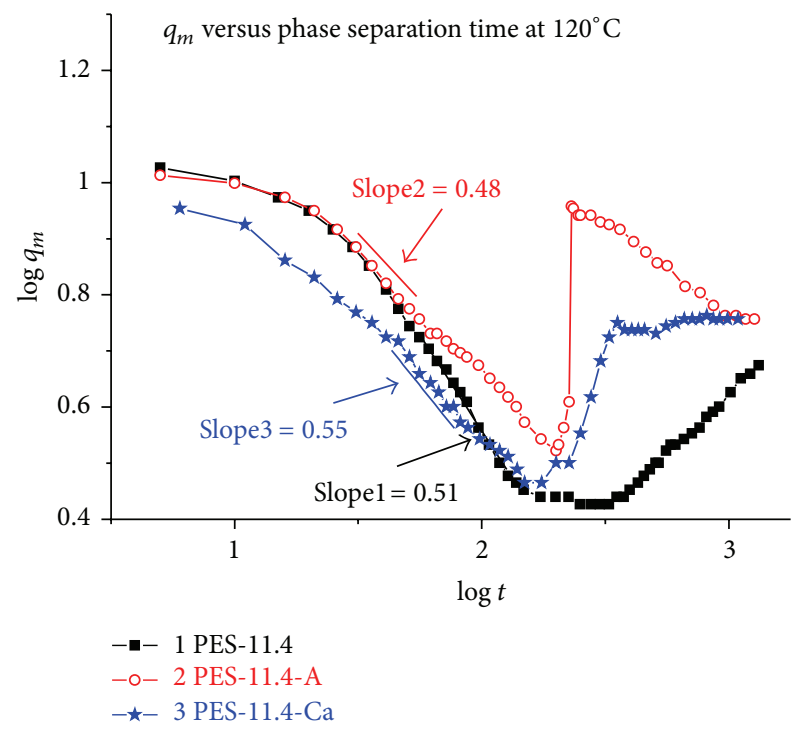

(a)

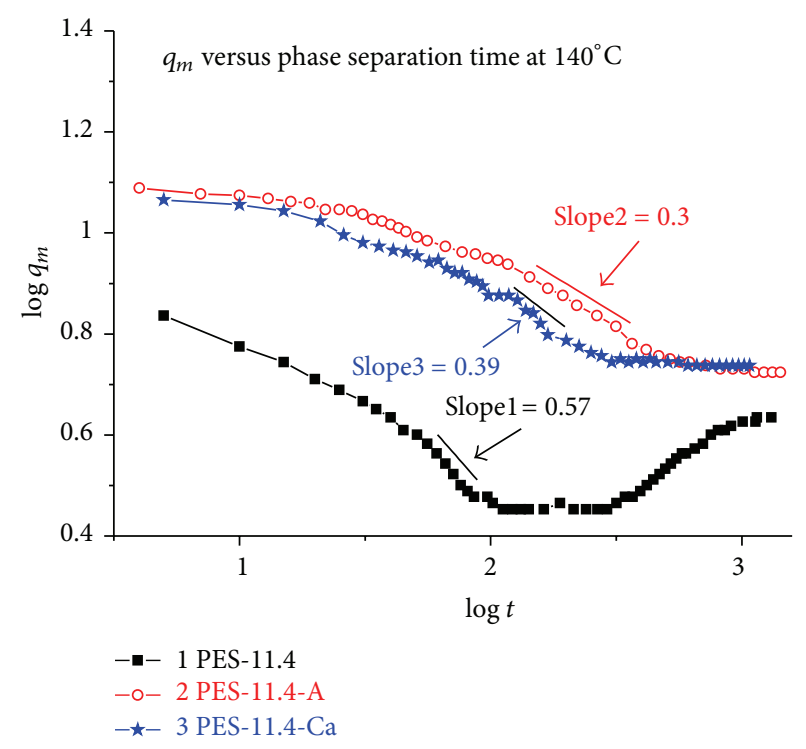

(b)

FIGURE 7: The changes of peak scattering vector, $q_{m}$, versus time of the blends of $11.4 \mathrm{wt} \%$ PES with and without fillers. (a) Cured at $120^{\circ} \mathrm{C}$, (b) cured at $140^{\circ} \mathrm{C}$.

while that of micron-sized fillers accelerates the phase separation a little due to the above-mentioned reasons. However, both the SEM and TRLS results show that the secondary phase separation disappeared at $120^{\circ} \mathrm{C}$ at the same time of morphology changes.

As to the effect of curing temperatures on the secondary phase separation, it is discussed before in our previous articles [34]. Hydrodynamic flow and diffusion are the main competition factors which affect the phase separation. If the size growth of the fast-dynamic-rich domain due to the hydrodynamic flow is too fast for the diffusion to keep up with the geometrical growth, secondary phase separation takes place; while no secondary phase separation occurs in the situation of the diffusion balanced geometrical growth systems.

The addition of mesoscale fillers shifts the PES-11.4 systems to normal SD process, and the formation of epoxyrich matrix along the filler percolation network entraps the PES-rich into particle structure. At lower temperature, the diffusion rate of epoxy and disentangle time of PES chains are not high enough to balance the hydrodynamic flow and growth of epoxy-rich matrix along filler networks, as a result, secondary phase separation takes place among the PES-rich particles. On the contrary, high curing temperature decreases system viscosity and increases the chain mobility sharply, while the percolation network formed by mesoscale fillers changes little at the same time, in this case, the diffusion of epoxy and disentangle of PES chains could follow the geometrical growth of epoxy-rich matrix, therefore no secondary phase separation takes place (Figure $7(\mathrm{~b})$ ).

In summery, the TRLS experimental results in Table 2 are quite consistent with the SEM and OM results. Nanoscale fillers enhance the viscoelastic phase separation to some extent, while the surface affinity of fillers also plays a crucial role in the phase separation process. For micron-sized
TABLE 2: Summary of the TRLS experimental results.

\begin{tabular}{lcccc}
\hline Blend & $\begin{array}{c}\text { Slope } \\
\text { (at } 120^{\circ} \mathrm{C} \text { ) }\end{array}$ & $\begin{array}{c}\text { Secondary } \\
\text { phase } \\
\text { separation }\end{array}$ & $\begin{array}{c}\text { Slope } \\
\text { (at 140 }{ }^{\circ} \mathrm{C} \text { ) }\end{array}$ & $\begin{array}{c}\text { Secondary } \\
\text { phase } \\
\text { separation }\end{array}$ \\
\hline PES-14.3 & 0.71 & $\checkmark$ & 0.89 & $\checkmark$ \\
PES-14.3-A & 0.41 & $\checkmark$ & 0.50 & $\checkmark$ \\
PES-14.3-Ca & 1.00 & $\checkmark$ & 1.09 & $\checkmark$ \\
PES-11.4 & 0.51 & $\checkmark$ & 0.57 & $\checkmark$ \\
PES-11.4-A & 0.48 & $\checkmark$ & 0.30 & $\times$ \\
PES-11.4-Ca & 0.55 & $\checkmark$ & 0.39 & $\times$ \\
\hline
\end{tabular}

$\checkmark$ : secondary phase separation occurs, $\times$ : does not occur.

fillers, the low surface area provides less entangle with the slow dynamic phase, and thus the surface affinity plays a more conspicuous role in phase separation. The preferential wetting of epoxy and its absorbing on the inorganic rods diminishes the viscoelastic effect and favours the growth of epoxy-rich particle size. The influence of mesoscale fillers on phase separation is a result of the competition between surface affinity and enhanced viscoelastic effect of the fillers. For low dynamic asymmetric systems, the effect of mesoscale fillers results mainly from its surface affinity. While high dynamic asymmetric systems would exhibit complicated phase separation behaviour due to the effects of both surface affinity and enhanced viscoelastic effect of the fillers.

\section{Conclusions}

The different effects of nanoscale (ATT) and microscale $\left(\mathrm{CaSO}_{4}\right)$ rod on the reaction-induced phase separation of Epoxy/PES blends originate from the surface affinity of fillers and chain entanglement of polymer chains with filler 
surfaces. The incorporation of mesoscale rod fillers does not change the spinodal decomposition mechanism of the blends with higher PES content than near-critical concentration, however, nanoscale fillers enhance the viscoelastic phase separation while micron-sized fillers also show dilute effect due to low surface area. For the blends with lower PES content than critical concentration of low dynamic asymmetry, the process of phase separation and final phase morphology are dramatically impacted by the incorporation of mesoscale rod fillers from their surface affinity to the epoxy-rich phase, especially when the filled blends are cured at higher temperature, which comes from the preferential wetting effect of inorganic rod percolation network on the epoxy-rich matrix.

\section{Acknowledgment}

This research work was supported by the National Nature Science Foundation of China (Grants 20674014 and 20974027).

\section{References}

[1] T. Inoue, "Reaction-induced phase decomposition in polymer blends," Progress in Polymer Science, vol. 20, pp. 119-153, 1995.

[2] P. A. Oyanguren, C. C. Riccardi, R. J. J. Williams, and I. Mondragon, "Phase separation induced by a chain polymerization: polysulfone-modified epoxy/anhydride systems," Journal of Polymer Science B, vol. 36, no. 8, pp. 1349-1359, 1998.

[3] A. Bonnet, J. P. Pascault, H. Sautereau, J. Rogozinski, and D. Kranbuehl, "Epoxy-diamine thermoset/thermoplastic blends: dielectric properties before, during, and after phase separation," Macromolecules, vol. 33, no. 10, pp. 3833-3843, 2000.

[4] K. Mimura, H. Ito, and H. Fujioka, "Improvement of thermal and mechanical properties by control of morphologies in PESmodified epoxy resins," Polymer, vol. 41, no. 12, pp. 4451-4459, 2000.

[5] B. Francis, G. Vanden Poel, F. Posada et al., "Cure kinetics and morphology of blends of epoxy resin with poly (ether ether ketone) containing pendant tertiary butyl groups," Polymer, vol. 44, no. 13, pp. 3687-3699, 2003.

[6] M. H. Wang, Y. F. Yu, X. G. Wu, and S. J. Li, "Polymerization induced phase separation in poly(ether imide)-modified epoxy resin cured with imidazole," Polymer, vol. 45, no. 4, pp. 12531259, 2004.

[7] I. A. Zucchi, M. J. Galante, and R. J. J. Williams, "Comparison of morphologies and mechanical properties of crosslinked epoxies modified by polystyrene and poly(methyl methacrylate)) or by the corresponding block copolymer polystyrene-b-poly(methyl methacrylate)," Polymer, vol. 46, no. 8, pp. 2603-2609, 2005.

[8] S. Maiez-Tribut, J. P. Pascault, E. R. Soulé, J. Borrajo, and R. J. J. Williams, "Nanostructured epoxies based on the self-assembly of block copolymers: a new miscible block that can be tailored to different epoxy formulations," Macromolecules, vol. 40, no. 4, pp. 1268-1273, 2007.

[9] Z. G. Xu and S. X. Zheng, "Reaction-induced microphase separation in epoxy thermosets containing poly( $\varepsilon$-caprolactone)-block-poly(n-butyl acrylate) diblock copolymer," Macromolecules, vol. 40, no. 7, pp. 2548-2558, 2007.

[10] M. Bakar, R. Duke, M. Przybylek, and M. Kostrzewa, "Mechanical and thermal properties of epoxy resin modified with polyurethane," Journal of Reinforced Plastics and Composites, vol. 28, no. 17, pp. 2107-2118, 2009.
[11] P. Jyotishkumar, C. Özdilek, P. Moldenaers et al., "Dynamics of phase separation in poly(acrylonitrile-butadiene-styrene)modified epoxy/DDS system: kinetics and viscoelastic effects," Journal of Physical Chemistry B, vol. 114, no. 42, pp. 13271-13281, 2010.

[12] Y. Zhang, F. H. Chen, W. C. Shi, Y. R. Liang, and C. C. Han, "Layered structure formation in the reaction-induced phase separation of epoxy/polysulfone blends," Polymer, vol. 51, no. 25, pp. 6030-6036, 2010.

[13] J. Fröhlich, R. Thomann, and R. Mülhaupt, “Toughened epoxy hybrid nanocomposites containing both an organophilic layered silicate filler and a compatibilized liquid rubber," Macromolecules, vol. 36, no. 19, pp. 7205-7211, 2003.

[14] Y. Ni, S. X. Zheng, and K. M. Nie, "Morphology and thermal properties of inorganic-organic hybrids involving epoxy resin and polyhedral oligomeric silsesquioxanes," Polymer, vol. 45, no. 16, pp. 5557-5568, 2004.

[15] M. A. Osman, V. Mittal, M. Morbidelli, and U. W. Suter, "Epoxylayered silicate nanocomposites and their gas permeation properties," Macromolecules, vol. 37, no. 19, pp. 7250-7257, 2004.

[16] S. Balakrishnan, P. R. Start, D. Raghavan, and S. D. Hudson, "The influence of clay and elastomer concentration on the morphology and fracture energy of preformed acrylic rubber dispersed clay filled epoxy nanocomposites," Polymer, vol. 46, no. 25, pp. 11255-11262, 2005.

[17] M. Peng, H. b. Li, L. J. Wu, Y. Chen, Q. Zheng, and W. F. Gu, "Organically modified layered-silicates facilitate the formation of interconnected structure in the reaction-induced phase separation of epoxy/thermoplastic hybrid nanocomposite," Polymer, vol. 46, no. 18, pp. 7612-7623, 2005.

[18] A. A. Asif, B. John, V. L. Rao, and K. N. Ninan, "Surface morphology, thermomechanical and barrier properties of poly(ether sulfone)-toughened epoxy clay ternary nanocomposites," Polymer International, vol. 59, no. 7, pp. 986-997, 2010.

[19] H. Tanaka, A. J. Lovinger, and D. D. Davis, "Pattern evolution caused by dynamic coupling between wetting and phase separation in binary liquid mixture containing glass particles," Physical Review Letters, vol. 72, no. 16, pp. 2581-2584, 1994.

[20] A. C. Balazs, V. V. Ginzburg, F. Qiu, G. W. Peng, and D. Jasnow, "Multi-scale model for binary mixtures containing nanoscopic particles," Journal of Physical Chemistry B, vol. 104, no. 15, pp. 3411-3422, 2000.

[21] V. V. Ginzburg, F. Qiu, M. Paniconi, G. W. Peng, D. Jasnow, and A. C. Balazs, "Simulation of hard particles in a phase-separating binary mixture," Physical Review Letters, vol. 82, no. 20, pp. 4026-4029, 1999.

[22] D. Suppa, O. Kuksenok, A. C. Balazs, and J. M. Yeomans, "Phase separation of a binary fluid in the presence of immobile particles: a lattice Boltzmann approach," Journal of Chemical Physics, vol. 116, no. 14, pp. 6305-6310, 2002.

[23] G. W. Peng, F. Qiu, V. V. Ginzburg, D. Jasnow, and A. C. Balazs, "Forming supramolecular networks from nanoscale rods in binary, phase-separating mixtures," Science, vol. 288, no. 5472, pp. 1802-1804, 2000.

[24] G. A. Buxton and A. C. Balazs, "Predicting the mechanical and electrical properties of nanocomposites formed from polymer blends and nanorods," Molecular Simulation, vol. 30, no. 4, pp. 249-257, 2004.

[25] S. W. Side, B. J. Kim, E. J. Kramer, and G. H. Fredrickson, "Hybrid particle-field simulations of polymer nanocomposites," Physical Review Letters, vol. 96, no. 25, Article ID 250601, 4 pages, 2006. 
[26] E. R. Soulé, J. Borrajo, and R. J. J. Williams, “Thermodynamic analysis of a polymerization-induced phase separation in nanoparticle-monomer-polymer blends," Macromolecules, vol. 40, no. 22, pp. 8082-8086, 2007.

[27] V. V. Ginzburg, "Influence of nanoparticles on miscibility of polymer blends. A simple theory," Macromolecules, vol. 38, no. 6, pp. 2362-2367, 2005.

[28] Y. F. Yu, M. H. Wang, W. J. Gan, Q. S. Tao, and S. J. $\mathrm{Li}$, "Polymerization-induced viscoelastic phase separation in polyethersulfone-modified epoxy systems," The Journal of Physical Chemistry B, vol. 108, no. 20, pp. 6208-6215, 2004.

[29] X. H. Zhong, Y. Liu, H. H. Su, G. Z. Zhan, Y. F. Yu, and W. J. Gan, "Enhanced viscoelastic effect of mesoscopic fillers in phase separation," Soft Matter, vol. 7, no. 7, pp. 3642-3650, 2011.

[30] Y. Liu, X. H. Zhong, G. Z. Zhan, Y. F. Yu, and J. Y. Jin, "Effect of mesoscopic fillers on the polymerization induced viscoelastic phase separation at near- and off-critical compositions," The Journal of Physical Chemistry B, vol. 116, no. 12, pp. 3671-3682, 2012.

[31] L. Zhao, G. Z. Zhan, Y. F. Yu, X. L. Tang, and S. J. Li, "Influence of attapulgites on cure-reaction-induced phase separation in epoxy/poly(ether sulfone) blends," Journal of Applied Polymer Science, vol. 108, pp. 953-959, 2008.

[32] K. Yamanaka and T. Inoue, "Structure development in epoxy resin modified with poly(ether sulphone)," Polymer, vol. 30, no. 4, pp. 662-667, 1989.

[33] H. Tanaka, "Viscoelastic phase separation," Journal of Physics Condensed Matter, vol. 12, no. 15, pp. R207-R264, 2000.

[34] X. L. Tang, L. X. Zhang, T. Wang, Y. F. Yu, W. J. Gan, and S. J. $\mathrm{Li}$, "Hydrodynamic effect on secondary phase separation in an epoxy resin modified with polyethersulfone," Macromolecular Rapid Communications, vol. 25, pp. 1419-1424, 2004. 

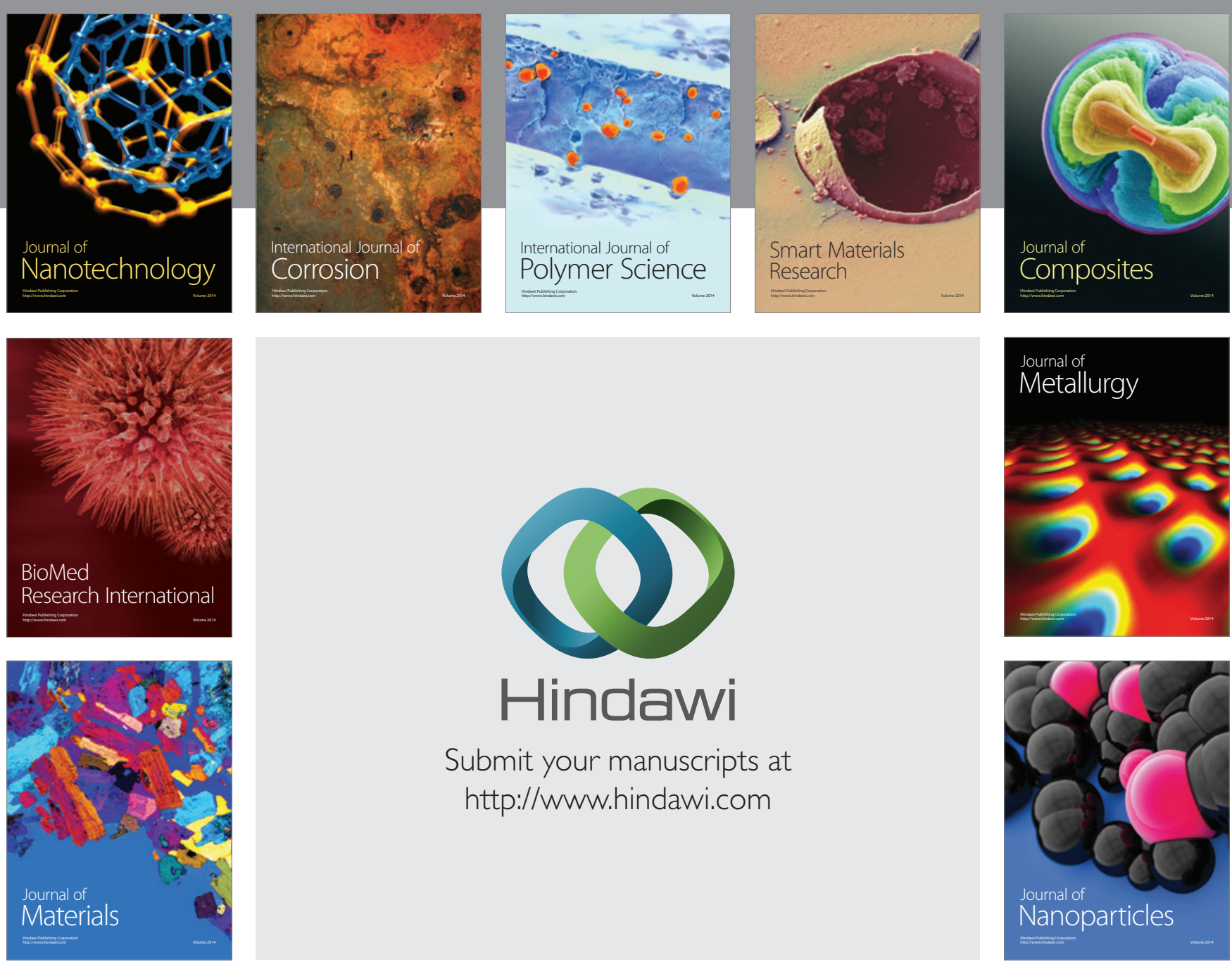

Submit your manuscripts at http://www.hindawi.com
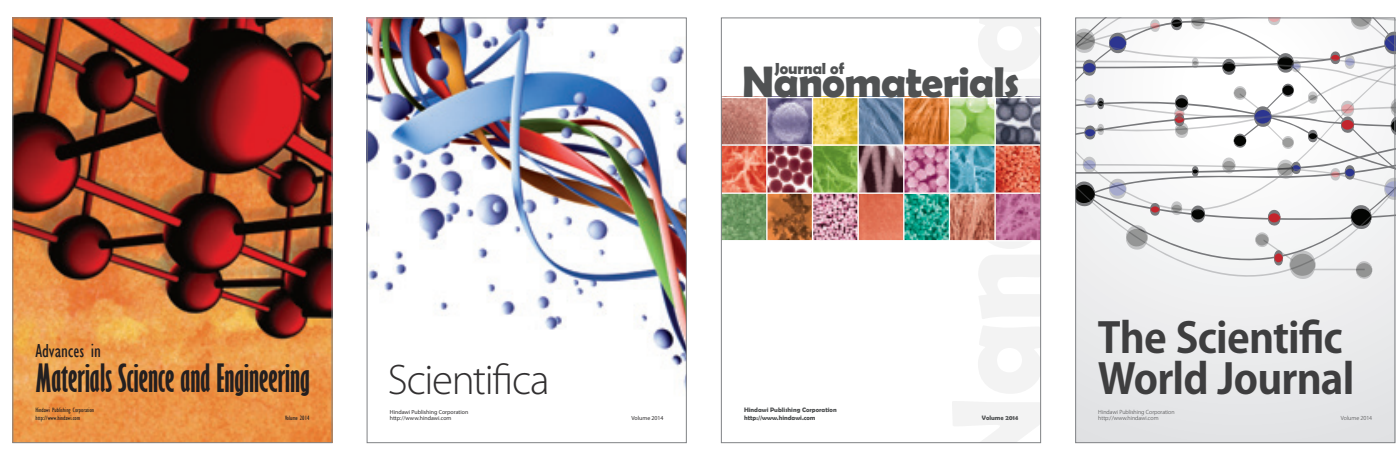

\section{The Scientific World Journal}
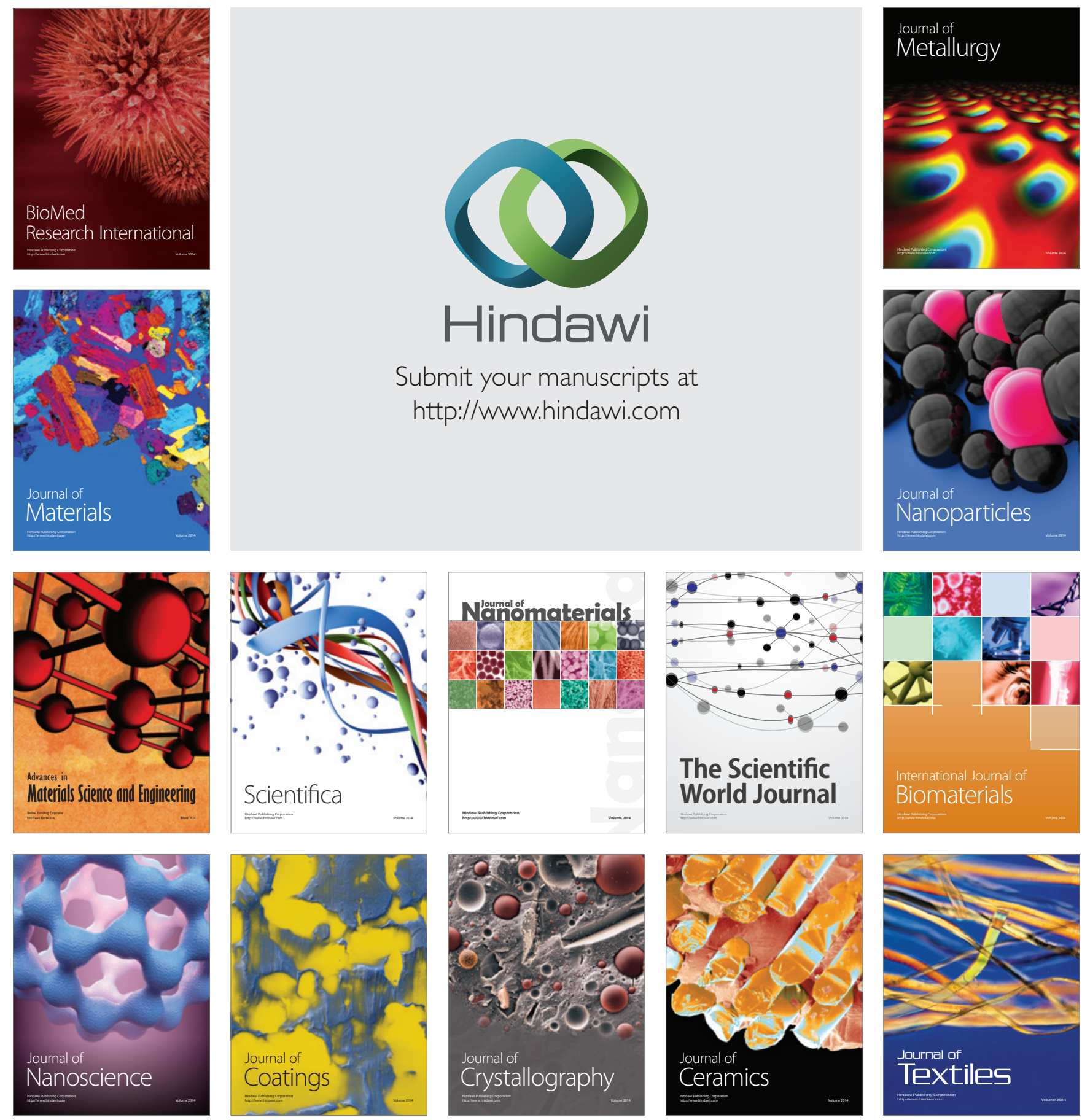